\title{
How Should the Effectiveness of Marine Functional Zoning in China Be Evaluated? Taking Wenzhou Marine Functional Zoning as an Example
}

\author{
Renfeng Ma ${ }^{1,2}{ }^{D}$, Jiarui Chen ${ }^{1}$, Qi Pan ${ }^{1}$, Yuxian Cheng ${ }^{1}$, Weiqin Wang ${ }^{1}$, Baoyu Zhu ${ }^{1}$, Jingwu Ma ${ }^{3}$ \\ and Jiaming $\mathrm{Li}^{4, *}$
}

1 Department of Geography and Spatial Information Techniques, Research Center for Land and Marine Spatial Utilization and Governance, Ningbo Universities Collaborative Innovation Center for Land and Marine Spatial Utilization and Governance Research, Ningbo University, Ningbo 315211, China; marenfeng@nbu.edu.cn (R.M.); 2011073014@nbu.edu.cn (J.C.); 2011087072@nbu.edu.cn (Q.P.); 2111073003@nbu.edu.cn (Y.C.); 2011073023@nbu.edu.cn (W.W.); 1911073024@nbu.edu.cn (B.Z.)

2 Donghai Academy, Ningbo University, Ningbo 315211, China

3 Natural Resources and Planning Bureau of Wenzhou, Wenzhou 325000, China; majingwu12@163.com

4 Institute of Geographic Sciences and Natural Resources Research, Chinese Academy of Sciences, 11A Datun Road, Beijing 100101, China

* Correspondence: lijm@igsnrr.ac.cn

\section{check for} updates

Citation: Ma, R.; Chen, J.; Pan, Q.; Cheng, Y.; Wang, W.; Zhu, B.; Ma, J.; Li, J. How Should the Effectiveness of Marine Functional Zoning in China Be Evaluated? Taking Wenzhou Marine Functional Zoning as an Example. Land 2022, 11, 267. https:// doi.org/10.3390/land11020267

Academic Editors: Wei Sun, Zhaoyuan Yu, Kun Yu, Weiyang Zhang and Jiawei Wu

Received: 11 January 2022

Accepted: 9 February 2022

Published: 10 February 2022

Publisher's Note: MDPI stays neutral with regard to jurisdictional claims in published maps and institutional affiliations.

Copyright: (c) 2022 by the authors. Licensee MDPI, Basel, Switzerland. This article is an open access article distributed under the terms and conditions of the Creative Commons Attribution (CC BY) license (https:/ / creativecommons.org/licenses/by/ $4.0 /)$.

\begin{abstract}
Marine functional zoning is a basic form of marine management proposed and organized by the Chinese government in the late 1980s, and the third round of planning and implementation has been completed. Effectiveness evaluation of marine functional zoning is an important tool to supervise the implementation of marine functional zoning and improve the level of marine management. For the first time, based on the concept of consistency, based on the planning blueprint, with the sea area use compliance, environmental quality compliance and development and utilization impact as the evaluation benchmark, this paper attempts to integrate and construct the coordination discrimination method of sea area utilization status and marine functional zoning, that is, the coordination index of marine functional zoning, and takes Wenzhou as an example. The research shows that the coordination index of marine functional zoning in Wenzhou is 0.81 during the planning period, and the implementation effect of marine functional zoning is good. Empirical research shows that this evaluation method can provide basic guidance for scientific compilation and effective implementation of marine spatial planning.
\end{abstract}

Keywords: marine functional zoning; implementation evaluation; blueprint; territorial space planning; Wenzhou

\section{Introduction}

Since the 21st century, the contradiction between the supply and demand of China's land resources has become increasingly fierce, resulting in the utilization of marine resources continuing to expand. The marine economy has grown into a new growth point of the national economy. However, the marine resource environmental bearing capacity is limited, and the unlimited use of coastal, island and sea areas will cause a series of marine environmental and economic problems (e.g., extensive and inefficient utilization of marine resources, increased environmental pollution, and ecosystem degradation). Therefore, sea area utilization needs scientific planning and guidance [1]. Marine functional zoning is an important tool for governments to optimize the utilization of marine resources and guide the sustainable development of the ocean by creating a spatial balance mechanism of marine utilization activities, coordinating the relationship between marine utilization demands and ecological environment protection, and seeking the harmonious development of marine resources and the environment and marine economy [2]. However, there is a 
problem of "emphasizing compilation and neglecting implementation" in China's existing marine spatial planning system, which makes it difficult for all marine spatial planning to give full play to the role of guiding marine economic activities [3]. Therefore, we constructed an evaluation method for the implementation of marine functional zoning and used Wenzhou City as an example to judge the coordination between the current sea area utilization and Wenzhou Marine Functional Zoning (2013-2020), which lays a foundation for the compilation of the marine part of Wenzhou's territorial spatial planning and provides a reference for future planning implementation evaluations.

The ocean is a complex system of water, including the marine life that lives in it, the atmosphere above the adjacent sea surface and the coasts and seafloor that surround it. Due to the fluidity of seawater, the ocean system is often more dynamic, connected, stratified and integrated. This makes it difficult to obtain marine ecological environmental factor data, and with changes in the observation scale, the data accuracy and application range will change greatly. Therefore, it is obviously very difficult to evaluate the implementation process of marine functional zoning, which is not yet operable enough. Therefore, the implementation evaluation of marine functional zoning should focus on result evaluation and adopt planning blueprints or planning targets as evaluation reference standards [4]. In view of the availability of empirical case data, this paper attempts to build the coordination discrimination method of marine functional zoning for the first time, that is, the coordination index of marine functional zoning, from three aspects: Compliance of sea area utilization, compliance of environmental quality standards and impact of development and utilization, and based on the concept of consistency and planning blueprint, Wenzhou was taken as an example. On the basis of solving the practical problems of Wenzhou marine spatial division, this paper aims to provide theoretical ideas and solutions for the implementation evaluation of marine spatial planning around the world, and promote the sustainable, efficient and reasonable development of global marine ecology.

\section{Literature Review}

\subsection{From Spatial Planning to Marine Spatial Planning}

Spatial planning is based on the concept of European Union integration and sustainable development. It is the geographical expression of economy, policy, culture and ecology in the time section to solve spatial connection and coordination [5-7]. In the process of the literature review, it was found that the connotation and scale of spatial planning are constantly developing and updating. In the early stage of development, spatial planning was a macroscale regional development strategy, and Strategic Spatial Planning Approach is the first to put forwards the coordination framework of European urban and regional planning based on the traditional land planning level. The European Spatial Development Perspective (ESDP), promulgated in 1999, further promotes multicentric, economically, socially and environmentally coordinated regional development through an integrated space policy $[6,8,9]$. With the development of economic globalization and sustainable development strategies, the emergence of "fuzzy space" and "space flow" has increased the complexity and uncertainty of spatial planning, and traditional strategic planning has gradually begun to spread to all scales [10].

At the same time, according to the 2005 report of the Millennium Ecosystem Assessment Plan and the Global and Regional Marine Environment Assessment Report, there is a deteriorating trend in the global coastal marine ecosystem affected by human activities [11]. Due to the high concentration of population and activities, the marine area faces great pressure, which has led to two kinds of main conflicts: first, the conflicts among human beings competing for the jurisdiction of marine space and the right to development; second, the conflicts of the increasing demand of humans being forced to further explore marine space and the decrease in marine biodiversity $[12,13]$. These conflicts may come from the time-space overlap of human activities at the sea or the externalities of positive and negative environments [14]. These conflicts reduce the biodiversity and robustness of marine areas, which will eventually affect the safety of human beings [15]. The conflict between 
the increase in human demand for developing marine space and the decrease in marine biodiversity has changed the sea through direct and indirect means in the development of the sea, challenging the existing institutional governance arrangements [16]. Therefore, marine-developed countries such as Europe and the United States have gradually formed the concept of marine space planning based on ecosystems and promoted the realization of integrated marine management based on ecosystems. Based on the theory and practical experience of urban and land spatial planning, the concept of spatial planning is applied to marine management. After continuous exploration, the concept of marine spatial planning is born. The world's marine spatial planning system has also been continuously optimized with the theoretical research, policy formulation and work practice of many experts, scholars and practitioners. To date, it has developed into a system that spans countries and focuses on marine spatial planning.

\subsection{Comparison of European Countries' Marine Spatial Planning and China's Marine Functional Zoning}

Foreign research on marine spatial planning started relatively early. After the introduction of the Convention on the Law of the Sea, the important role of marine spatial planning in marine development and protection has gradually been realized [17]. Approximately half of global marine spatial planning is formulated in the European Union [18]. The introduction of Agenda 21 in 1992 prompted the EU to rethink the management of the oceans and seas and put forwards corresponding suggestions and initiatives; from 2002 to 2007, Integrated Coastal Zone Management Proposals, Future-oriented EU Ocean Policy: European Ocean Vision and Blue Book on Integrated Ocean Policy were issued, further clarifying the macro guidance role of ocean space planning [19-22]. In 2014, Directive 2014/89/EU of the European Parliament and the Council (EP\&C) was enacted and established a common framework for marine spatial planning (MSP), targeting sustainable development of marine economies and sea areas; as well as the sustainable utilization of marine resources, it has been the main policy instrument in Europe [13]. Overall, EU marine spatial planning is gradually shifting from a single environmental control tool to a multipurpose marine space governance tool with blue growth as the core.

In the past 20 years, EU countries have also carried out their own practice of sea area spatial planning and have achieved remarkable results. They preliminarily completed sea area utilization planning and zoning within their territorial waters and formed a complex multilevel and multiscale "local-regional-national-international" planning and management system of. Britain is a traditional maritime power, and over the last decade it has been working to optimize and improve its marine management. Based on the land-use planning system and marine characteristics, Tyldesley proposed a framework concept for the UK marine spatial planning system, forming a marine spatial planning system that includes four levels: the United Kingdom, National, Regional and Local [23]. Based on the study of this framework concept, the United Kingdom has gradually carried out practical work on marine spatial planning and system construction. The implementation of the British Coastal Zones and Ocean Access Act in 2009 reversed the fragmentation of ocean management and clarified the management authority of British maritime areas (territorial waters, exclusive economic zones and continental shelf) to provide an institutional basis for the establishment of a marine spatial planning system. In 2011, the UK issued the UK Marine Policy Statement, proposing the need to establish a marine planning system and clarifying the principles, contents and policies of marine (space) planning [24-26]. According to the plan, the UK will complete the marine spatial planning of all jurisdictions by 2021. The Master Plan was established in 2003 by Belgium, which was one of the earliest countries to carry out a multipurpose sea area planning system in its territorial waters (TS) and exclusive economic zone (EEZ) [27]. The Netherlands established the North Sea 2015 Integrated Marine Management Plan for the effective use of marine resources, and marine space management is the key means of the plan [28]. In July 2004, Germany extended federal spatial planning acts to the EEZ, established a general framework for marine spatial 
planning in the EEZ, and completed a draft marine spatial plan for the North Sea and Baltic Sea and related environmental reports in 2005 [29].

Compared with foreign experience in marine spatial planning, the basic objectives and guiding ideology of marine spatial planning measures or plans adopted in the use and management of sea area abroad are similar to those of China's marine functional zoning [30]. The main objectives of marine spatial planning and functional zoning emphasize guiding the rational development and utilization of the sea and protecting the marine environment. Marine functional zoning divides the sea into functional zones with different types of use and different environmental quality requirements according to the geographical location of the sea, the natural environment and resources, the development and utilization and protection of the current situation and economic and social development needs [31]. Since China carried out investigation and research in the 1980s, three rounds of marine functional zoning have been prepared and implemented, and a complete planning system has been established. On the basis of marine functional zoning, the former State Oceanic Administration formulated normative documents such as Regulations on the Management of Marine Functional Zoning and implemented a series of management systems such as approval and paid use of sea area. At the same time, compared with foreign marine spatial planning, China's marine functional zoning has a higher legal status and a comprehensive range of implementation. The Law of the People's Republic of China on the Administration of Sea Use stipulates that the state implements a system of marine functional zoning, and the use of sea area must comply with marine functional zoning. The Law of the People's Republic of China on Marine Environmental Protection takes marine functional zoning as the basis for supervision and management of the marine environment. The Law of the People's Republic of China on the Protection of Sea Islands takes marine functional zoning as the basis for the preparation of island protection planning. The State Council, in its approval of the National Marine Functional Zoning (2011-2020), emphasizes that marine functional zoning is the legal basis for rational development and utilization of marine resources and effective protection of the marine ecological environment and must be strictly implemented [32,33]. In summary, both marine spatial planning and marine functional zoning play an important role in strengthening the management of sea area use, coordinating the contradiction of sea use and protecting the marine ecological environment.

\subsection{Evaluation Mechanism for Spatial Planning Implementation}

Foreign spatial planning has a long history of development and a mature system, which has formed a systematic evaluation mechanism for planning implementation, mainly with two basic evaluation concepts of "conformance" and "performance" [34]. The concept of "conformance" focuses more on the effect of planning implementation, and there are two main methods of evaluation: one is to take the planning blueprint as the ultimate goal, compare the results of planning implementation with the blueprint, and analyze the effectiveness of planning implementation; the other is to start from the planning goals, and study the implementation of central and local planning goals in specific areas [35-38]. The concept of "performance" focuses more on the implementation process of the plan, and believes that the result of the plan is not entirely consistent with the blueprint of the plan, but more crucial is the role of the plan itself in guiding the decision-making process of regional development, including three aspects: first, the government's decisions are mainly made with reference to the plan; second, although some of the government's decisions are not in line with the content of the plan, they are made after careful consideration based on the plan and are consistent with the intent of the plan; third, the rapid development of the region makes it difficult to meet the actual needs of the plan, and the government's decisions are first revised in the plan [39,40].

The implementation evaluation of spatial planning in China mainly focuses on land use planning and urban planning but rarely involves marine area planning. The research focuses on evaluating the results, benefits and impacts of the implementation of planning. The research method is to establish a system of indicators for evaluating the implementation 
of the plan and to determine the weights of the indicators by using the Delphi method or hierarchical analysis to comprehensively evaluate the specific situation and problems of the implementation of the plan and then make recommendations for the revision of the plan. The assessment concept is mainly based on the assessment of planning implementation results. Although the importance of the assessment of the planning implementation process has been noted, less research has been conducted due to uncertainty and difficulty of operation, and the existing assessment of the planning implementation process focuses on the analysis of the formulation of planning implementation policies and institutional construction, as well as a brief qualitative analysis of the influencing factors of planning implementation [41,42].

\section{Construction of the Evaluation Method for Marine Functional Zoning}

Implementation evaluation is one of the basic links in marine functional zoning management, and its implementation is conducive to promoting marine functional zoning to give full play to its function of optimizing marine resources and guiding the marine economy. The implementation evaluation of marine functional zoning is mainly based on the concept of consistency, with the result evaluation as the main criterion and the planning blueprint or planning objective as the evaluation criterion. This paper discusses the implementation evaluation method of marine functional zoning based on blueprints (Figure 1).

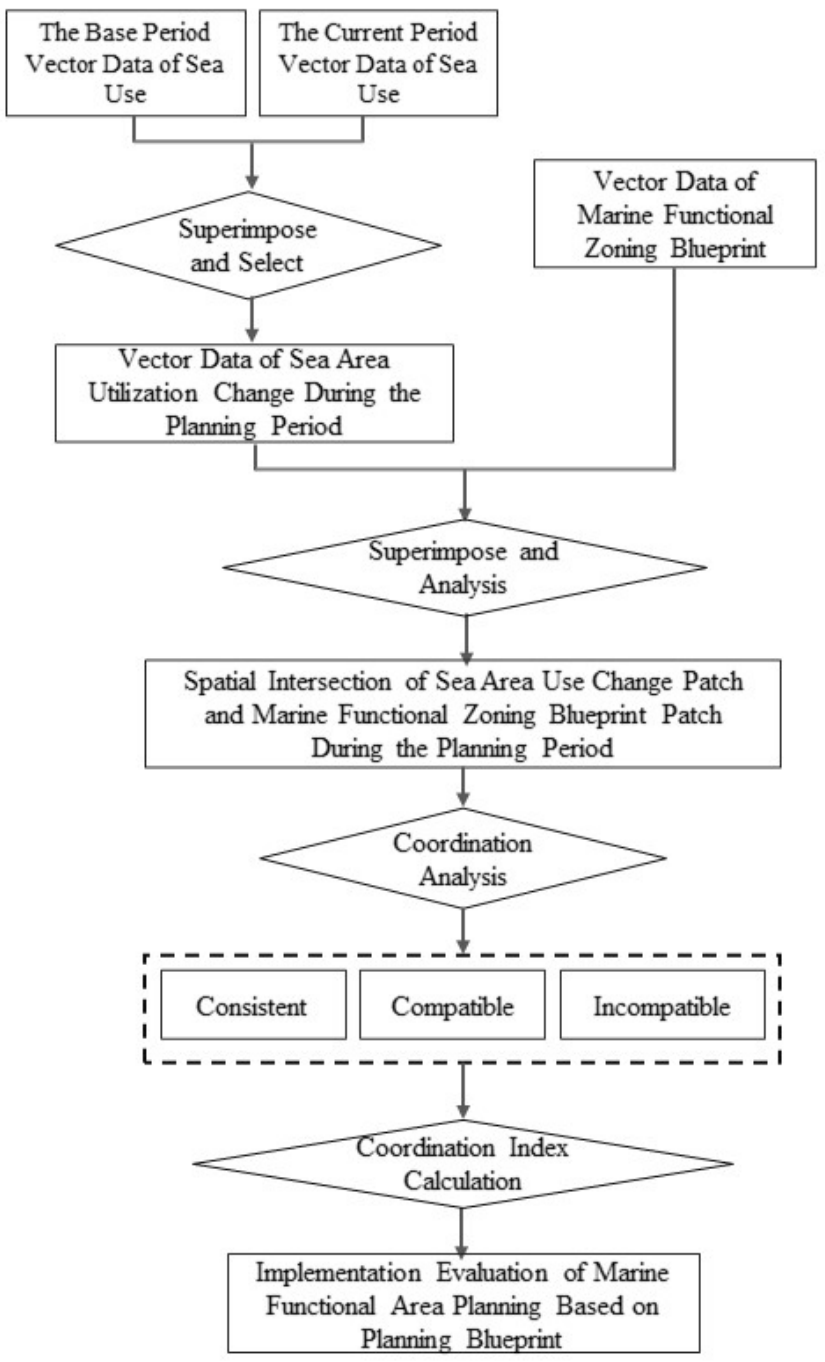

Figure 1. Implementation evaluation of marine functional zoning based on planning blueprints. 
First, geographic information system (GIS) software was used to superimpose the vector data of sea use between the base period and the current period, and then we removed the patches that did not change in the type of sea use from the base period to the current period to obtain the data of patches that changed in sea use during the planning period. Second, the spatial relationship between the change in the patch of sea area and the patch of marine function division was obtained using GIS software, including "coincidence", "intersection", "inclusion", "adjacency" and "separation" [43]. "Coincidence" means that the shape, size and spatial position of the two planar patches are completely consistent. "Intersection" refers to two planar patches that do not coincide but overlap in space. "Contained" means that one facet plaque is completely inside another; "Adjacency" means that two planar patches have a common boundary and do not intersect internally. "Dissociation" means that the intersection of two planar plaques is an empty set. Third, the coordination between the patch with an "intersecting" or "containing" relationship and the patch with marine functional zoning is judged; that is, the degree to which the indicators of a patch's use activity meet the function and control requirements stipulated by marine functional zoning. The complexity of marine resources determines the multifunctionality of the sea area, which in turn leads to the existence of one or more compatible functions in the same sea area, such as the establishment of small fishing docks in aquaculture areas to facilitate the transportation of raw materials and aquaculture products [44].

The main considerations of coordination discrimination are whether the marine utilization activities conform to the use control of marine functional zoning, whether they serve the dominant function of the zoning, whether they cause irreversible changes to the basic function of the zoning and whether the environmental protection requirements and environmental quality standards of the zoning are implemented [45]. Therefore, coordination can be divided into "consistent, compatible and uncoordinated" types. "Consistent" means that the sea area utilization type is similar to the zoning type, and all indicators fully meet the zoning use control and environmental protection requirements. "Compatible" means that although the sea area utilization type is not consistent with the zoning type, it can serve the formation of the dominant function of the functional zoning and meet the environmental quality standards of the functional zoning, for example, the construction of small tourist docks in the tourism and entertainment area; "Uncoordinated" means that the type of sea area utilization will cause irreversible changes to the basic functions of the zoning function zoning, or the environmental quality standard of sea area utilization does not meet the control requirements of the zoning function. For example, the construction of ports will change the natural background and water environment of the sea area, so it cannot be carried out in the aquaculture area or the breeding area.

Finally, the coordination index of marine functional zoning implementation is calculated according to the coordination between the current patch and the planned patch, and the implementation effect of marine functional zoning is judged comprehensively.

\subsection{Spatial Relationship between Sea Area Use Change Patches and Blueprint Patches}

The spatial relationship between the patch of sea area use change and the patch of blueprint includes five types: "overlap", "intersection", "inclusion", "adjacency" and "separation" (Table 1). The spatial relationship definition is mainly completed by using the spatial overlay tool in ArcGIS10.2 software. If the shape, size and space position of the two are exactly the same after superposition, it is "coincidence". If the two planar patches do not coincide but overlap in space, it is "intersecting"; if a facial-shaped patch is completely inside another facial-shaped patch, it is "contained"; if two planar patches have a common boundary and do not intersect internally, it is "adjacent". If the intersection of two planar plaques is an empty set, it is referred to as "phase separation". 
Table 1. Spatial relationship types of sea area use change patches and planning blueprint patches.

\begin{tabular}{|c|c|c|c|}
\hline Spatial Relationship Type & Meaning & \multicolumn{2}{|c|}{ Sketch } \\
\hline Overlap & Patch A and patch B completely coincide & \multicolumn{2}{|c|}{ A/B } \\
\hline Intersection & Patch A partially overlaps with patch B & A & B \\
\hline Inclusion & Patch B is inside patch A & \multicolumn{2}{|c|}{${ }_{A} B$} \\
\hline Adjacency & $\begin{array}{l}\text { Patch A and patch B have a common boundary } \\
\text { and no overlap inside }\end{array}$ & A & B \\
\hline Separation & The intersection of patch A and patch B is empty & A & $\mathrm{F}$ \\
\hline
\end{tabular}

\subsection{Coordination between Sea Area Use Change Patches and Planning Blueprint Patches}

Coordination discrimination mainly includes the discrimination of conformity of sea area use, the discrimination of conformity of sea area environmental quality standard and the discrimination of the influence of sea area utilization. In terms of the discrimination steps, the first criterion should be the conformity of sea use, that is, whether the use type is consistent or similar to the functional zoning type; if not, the coordination is "consistent"; if not, the next criterion should be carried out. The second step is to judge whether the environmental quality standard of the sea area utilization type meets the environmental protection control requirements of functional zoning. If so, the third step is to judge whether the coordination is "uncoordinated". The third step is to determine whether the sea area utilization type will cause irreversible changes to the basic functions of zoning function zoning. If so, the coordination is "uncoordinated"; if not, the coordination is "compatible".

\subsection{Coordination Index of Marine Function Regionalization}

According to the coordination index, the implementation effect of marine function zoning is comprehensively judged, and the calculation is shown in Formula (1), where $\mathrm{W}$ is the coordination index, $\mathrm{N}$ represents the spatial relationship of patches, where the values of "overlap", "intersection" and "inclusion" are 1 and the values of "adjacency" and "separation" are 0. S1, S2 and S3 are patch areas with "consistent", "compatible" and "incompatible" coordination, respectively. S4 is the total area of sea use change patches; A reflects the level of conflict between sea area utilization type and zoning blueprint, among which the impact of development and utilization of marine reserves is the most serious, which is set as 0.00 ; the influence of the fishery sea being developed into construction sea (such as industrial sea) or construction sea being developed into fishery sea is the next, with 0.25 .

$$
\mathrm{W}=\mathrm{N} \times\left(\mathrm{S} \_1 \times 1.00+\mathrm{S} \_2 \times 0.50+\mathrm{S} \_3 \times \mathrm{A}\right) / \mathrm{S} \_4
$$

Figure 2 shows the implementation evaluation logic of marine functional zoning based on the planning blueprint. First, the blueprint data of marine functional zoning and the change data of sea area utilization are overlapped in space. Activity of Marine functional areas-A Marine use C, Marine functional areas using active D, Marine functional areas, Marine B-Marine use C, Marine functional areas, Marine use D superposition of four 
kinds of results, analysis and coordination and calculated Marine functional zoning index W, coordination of the Marine functional zoning implementation effect assessment (Table 2).
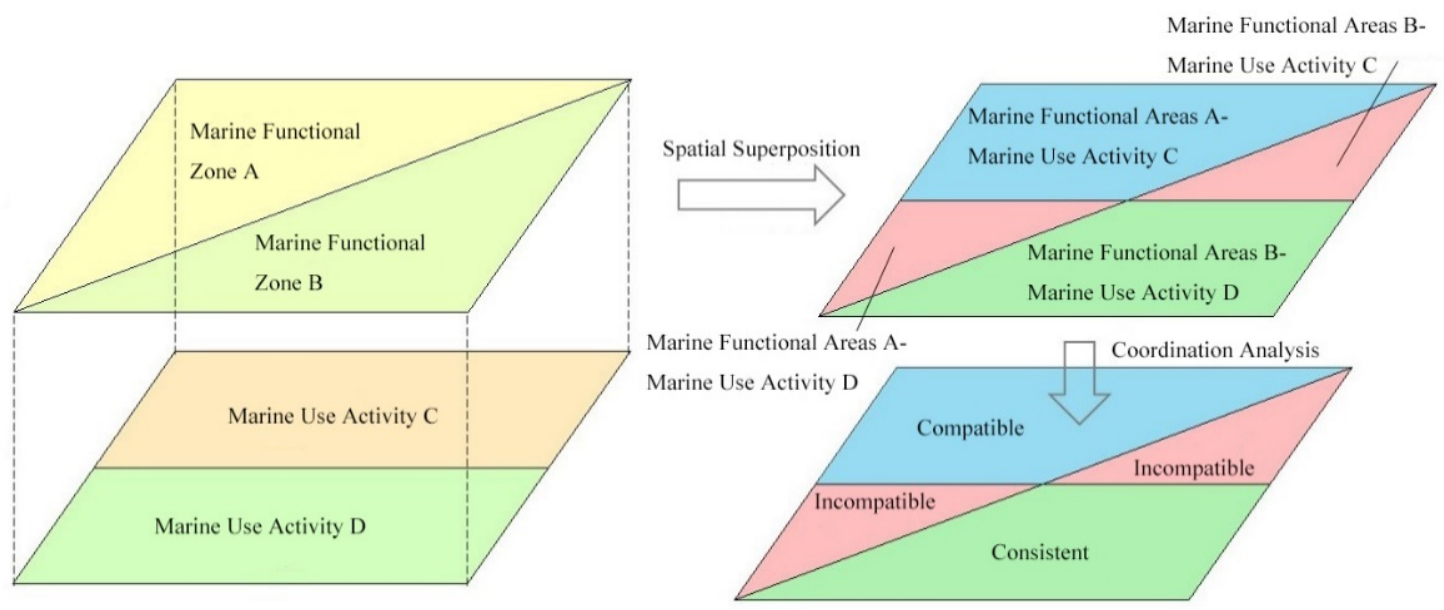

Figure 2. An example of implementation evaluation of marine functional zoning based on planning blueprints.

Table 2. Evaluation criteria for the implementation effect of marine functional zoning.

\begin{tabular}{cc}
\hline Index of Coordination of Marine Functional Zoning (W) & Implementation Effect of Marine Functional Zoning \\
\hline $\mathrm{W}=1$ & Completely consistent \\
$0.8 \leq \mathrm{W}<1$ & Preferably \\
$0.6 \leq \mathrm{W}<0.8$ & Commonly \\
$0.4 \leq \mathrm{W}<0.6$ & Poor \\
$\mathrm{W}<0.4$ & Range \\
\hline
\end{tabular}

\section{Implementation Evaluation of Marine Functional Zoning of Wenzhou City (2013-2020) Based on the Planning Blueprint}

\subsection{Marine Functional Zoning of Wenzhou City (2013-2020) Blueprint for Functional Zoning}

Marine Functional Zoning of Wenzhou City (2013-2020) was implemented in 2013 to coordinate and regulate various types of marine activities in Wenzhou, strengthen the protection of marine resources and the environment, promote the construction of marine economic development demonstration zones and serve as the basis for the city's marine development and utilization, management and protection. Marine Functional Zoning of Wenzhou (2013-2020), which refers to Technical Requirements for the Preparation of Provincial Marine Functional Zoning and Technical Requirements for the Preparation of Municipal and County-level Marine Functional Zoning in Zhejiang Province, divides the Wenzhou sea area into eight first-class functional zones, including an agriculture and fishery zone, a port and shipping zone, an industry and urban sea zone, a tourism and recreation zone, a marine protection zone, a special use zone, a mineral and energy zone, and a reserved zone, and 23 second-class functional zones under them. According to the vector data provided by the Wenzhou Bureau of Natural Resources and Planning, the blueprint structure of 2020 Wenzhou marine functional zones estimated in Wenzhou Marine Functional Zoning (2013-2020) is shown in Table 3, in which the area of agriculture and fishery zones is the largest, accounting for $75.04 \%$, which is because most of the sea area that are not suitable for development and construction and have no outstanding ecological and environmental protection value are delimited as fishing zones. The area of reserved zones is the second, accounting for $13.65 \%$, which is mainly located in the periphery of the marine-protected zones and exists as a buffer zone of the marine protected zones. The area of port shipping zones is next, accounting for 5.81\%, mainly including Yueqing, Dongtou, Oujiang Estuary, Feiyun River, Aojiang Estuary, Pacao, Xiaguan and seven other port zones, seven channel 
zones and eight anchor zones. Marine-protected zones accounted for 3.01\% of the area, including Ximen Island, east of Dongtou Islands, Nance Island, Wenzhou Shupaisha Island, Nanji Islands, North and South Pan Mountain, Tongpan Island, and Qixing Island. Industrial and urban sea zones, tourism and recreation zones, mineral and energy areas, and special use zones accounted for $2.49 \%$ of the total area (Figure 3 ).

Table 3. The structure of functional zones in Wenzhou Marine Functional Zoning (2013-2020).

\begin{tabular}{ccc}
\hline Functional Zone Type & Proportion of Functional Zones/\% & $\begin{array}{c}\text { Proportion of the Number of Map } \\
\text { Spots in Functional Zones/\% }\end{array}$ \\
\hline Agricultural and fishery zone & 75.04 & 25.93 \\
Reserved zone & 13.65 & 18.52 \\
Port and shipping zone & 5.81 & 16.67 \\
Marine-protected zone & 3.01 & 14.81 \\
Industrial and urban sea zone & 1.82 & 12.96 \\
Tourism and recreation zone & 0.58 & 5.56 \\
Special use zone & 0.08 & 3.70 \\
Minerals and energy zone & 0.01 & 1.85 \\
Total & 100.00 & 100.00 \\
\hline
\end{tabular}

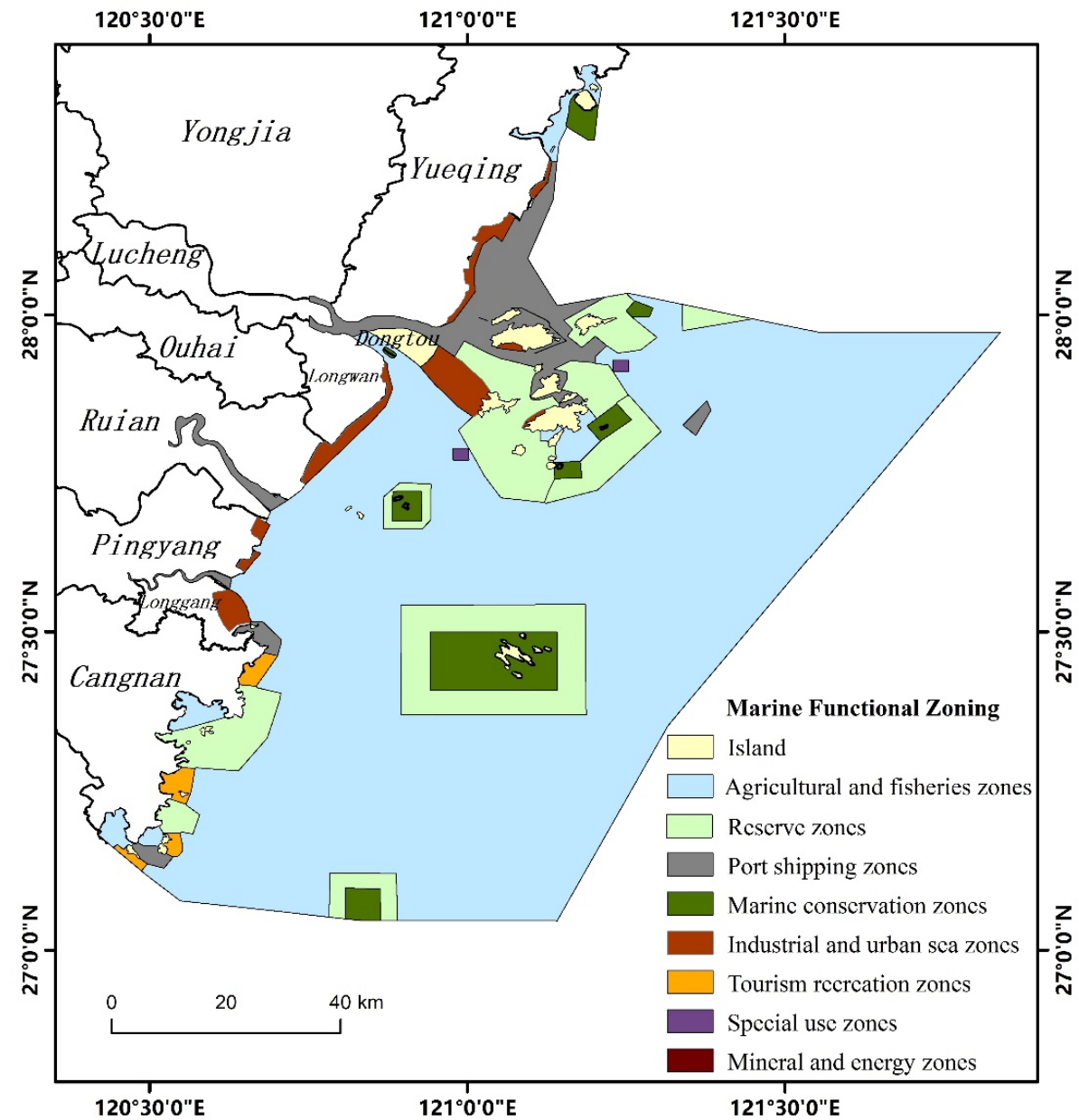

Figure 3. Blue print of functional zones of Wenzhou Marine Functional Zoning (2013-2020).

\subsection{Sea Area Utilization of Wenzhou City from 2013 to 2020}

According to the standard of Sea Area Use Classification (HYT 123-2009), the sea area use data types of Wenzhou are divided into eight first-class sea areas for fishery, industry, tourism and entertainment, transportation, land engineering, special use, undersea engi- 
neering and other uses, and 18 second-class areas. The vector data of 2013 and 2020 sea area utilization from the dynamic management system of sea area utilization in Wenzhou were imported into ArcGIS10.2 software, and the patches with no change in sea area utilization type were eliminated. After that, the spatial vector attributes of various sea area utilization and map spots in Wenzhou from 2013 to 2020 could be obtained statistically (Table 4). From 2013 to 2020, sea area utilization structure of Wenzhou was mainly composed of fishery seas (25.63\%), industrial seas (21.81\%) and transportation seas (35.52\%). Among them, the sea used for fisheries is mainly used for aquaculture and open aquaculture. The sea used for aquaculture is mainly distributed in Yongxing Street, Haibin Street, Xinghai Street and Haixi Town of Pingyang County in the Longwan District, and a small amount is distributed in Beiao Street of Dongtou Island and the coast of Gate Town of Gate Island. Open aquaculture seas are mainly distributed in Xinghai Street, Yongxing Street and other mainland coastal areas of the Longwan District, and small amounts are found in Nanji town of Nanji Island, Luxi township of Luxi Island, Ximen Island (Yandang town) and Daqu village of Daqu Island. The industrial sea is mainly used for the electric power industry and is mainly distributed in Yanting town of Longgang city, Nanyue town of Yueqing city and other continental coastal areas. Transportation by sea includes a port with sea and road and a bridge with sea, a port with sea distribution in oujiang, Feiyun River, Aojiang and Zhuangyuan Ao Island, Xiaoming Island, Gate Island and other island coast and Yueqing City Of Nanyue town and Puqi town; road and bridge sea for the Yongdong-Dongguan highway cross-sea sections, distribution in the Oujiang mouth, Feiyun river mouth, Aojiang mouth and Dayuwan, Wenzhou City internal cross-sea, a cross-river bridge, such as Oujiang mouth rail transit S1 line, Ni Yu Island and the Dongtou gorge on the S77 provincial road extension line Longwan to the Dongtou Shugang highway project (Figure 4).

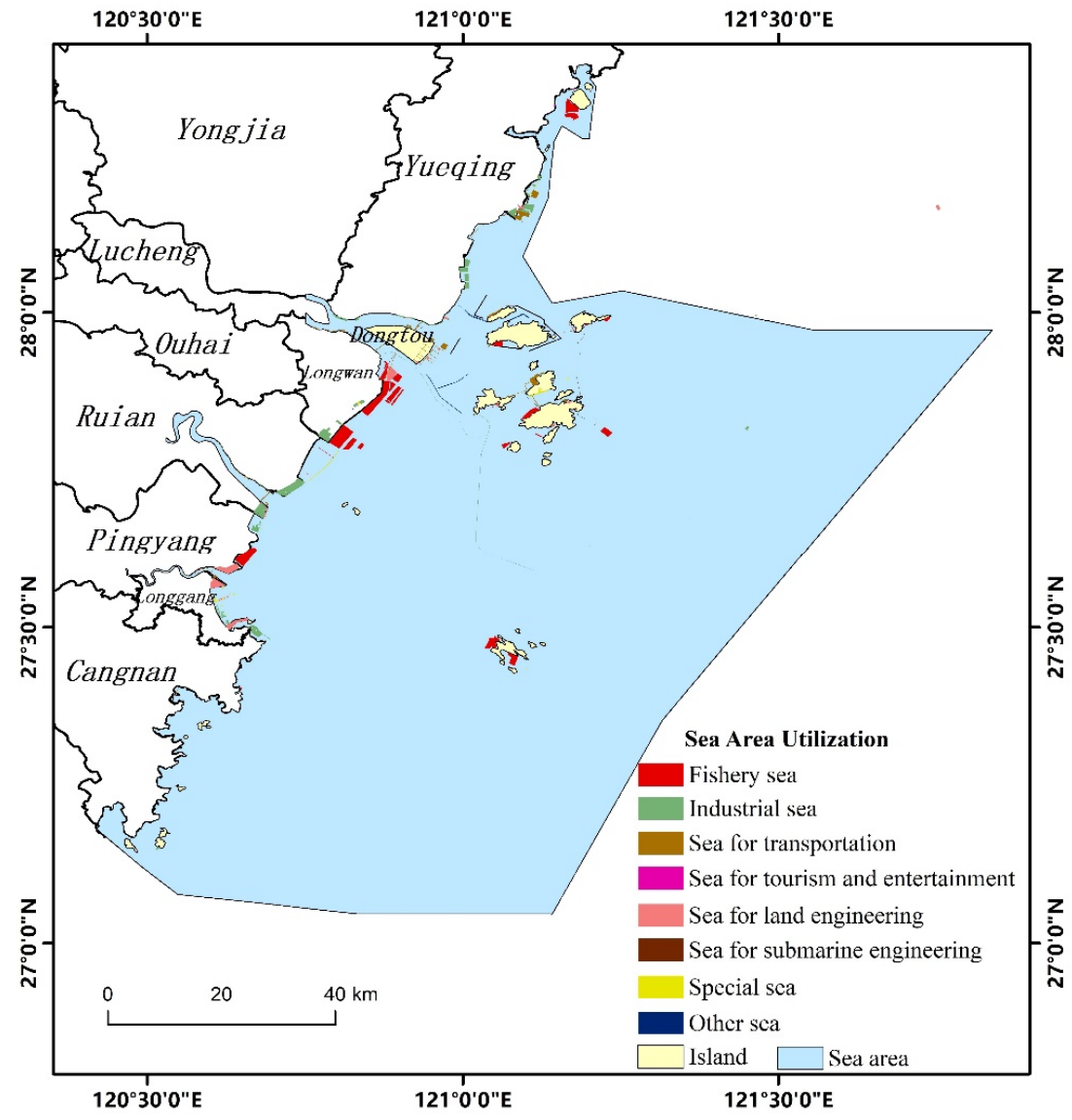

Figure 4. Sea area utilization in Wenzhou from 2013 to 2020. 
Table 4. The utilization structure of sea area in Wenzhou from 2013 to 2020.

\begin{tabular}{ccc}
\hline Type of Sea Area & Percentage of Sea Parcel Number/\% & Percentage of Sea Parcel Area/\% \\
\hline Fishing in the sea & 18.33 & 25.63 \\
Industrial use sea & 21.00 & 21.81 \\
Sea for transportation & 45.33 & 35.52 \\
Sea for land engineering & 3.83 & 6.60 \\
Special sea & 4.83 & 6.12 \\
Other sea & 1.83 & 2.74 \\
Sea for submarine engineering & 3.50 & 1.39 \\
Sea for tourism and entertainment & 1.33 & 0.19 \\
Total & 100.00 & 100.00 \\
\hline
\end{tabular}

\section{Discussion}

The marine functional zoning of Wenzhou city (2013-2020) was compiled according to the classification system of Technical Requirements for Marine Functional Zoning at the provincial level and Technical Requirements for Municipal and County-level Marine Function Zoning at the Zhejiang Province, while the sea area utilization data from 2013 to 2020 were compiled according to the standard of Sea Area Use Classification (HYT 123-2009). Therefore, it is necessary to distinguish the coordination between the two classification systems. It should be pointed out that the blueprint of Wenzhou City Marine Functional Zoning (2013-2020) does not subdivide the industrial and urban construction areas and tourism, leisure and entertainment areas into the second class, so the discrimination process is not differentiated. In ArcGIS10.2, the marine utilization data from 2013 to 2020 and vectorized blueprint data of 2020 are analyzed for spatial superposition and coordination, and the coordination index of marine functional zoning is calculated to be 0.81 , indicating that the implementation effect of Wenzhou Marine Functional Zoning (2013-2020) is good. The proportions of plaque areas with "consistent", "compatible" and "incompatible" characteristics were $69.42,14.87$ and $15.71 \%$, respectively. The patch area of the "compatible" type accounted for $14.87 \%$, mainly including mixed utilization between ports, urban construction, fishery infrastructure and stratified mixed utilization between waterways, undersea tunnels, roads and bridges, indicating that Wenzhou's marine economy has achieved some results in the mixed utilization and stratified three-dimensional utilization of sea areas. However, the level of mixed utilization and three-dimensional utilization is still low (Figure 5).

The concept of consistency can accurately determine the deviation between the initial planning and the implementation results and then provide a basis for the revision and rearrangement of the planning, which is the most widely used logical thinking in China's existing planning evaluation practice [46,47]. Due to the complexity and continuity of marine systems and the limited monitoring data of marine areas, the implementation evaluation of marine functional zoning should be based on the concept of consistency and adopt the blueprint or target as the evaluation reference standard. Based on the concept of consistency and the marine functional zoning blueprint, this paper discriminates the coordination between marine use and the marine functional zoning blueprint from three aspects: conformity of marine use, conformity of environmental quality standards, and influence of development and utilization, and calculates the coordination index of marine functional zoning to construct the implementation evaluation method of marine functional zoning. The method has two advantages: first, it is easy to obtain data, and the evaluation only needs the vector data of the current situation of marine utilization and the vector data of the blueprint of marine functional zoning. The collection and maintenance of such data is one of the basic tasks of the local marine management departments. Second, it is easy to operate. This method can be realized with the help of common geographic information system software (such as ArcGIS). The operation steps are simple and easy to get started. Therefore, this method has strong scientific applicability, operability and extensibility and can provide a reference for the implementation and evaluation of marine functional 
zoning in various areas. At the same time, this method also found some disadvantages in the empirical process. In the process of judging the coordination between marine area utilization change patches and planning blueprint patches, the main way to judge the impact of sea area utilization is expert scoring, which is subjective and may affect the accuracy and objectivity of the evaluation results. After that, in the process of research and demonstration, it is necessary to establish an objective and efficient evaluation system. AHP, a matter-element model and other methods can be used for multi-factor evaluation and standard grading, and socio-economic data can be used instead of experts' scoring so as to improve the objectivity of the evaluation system.

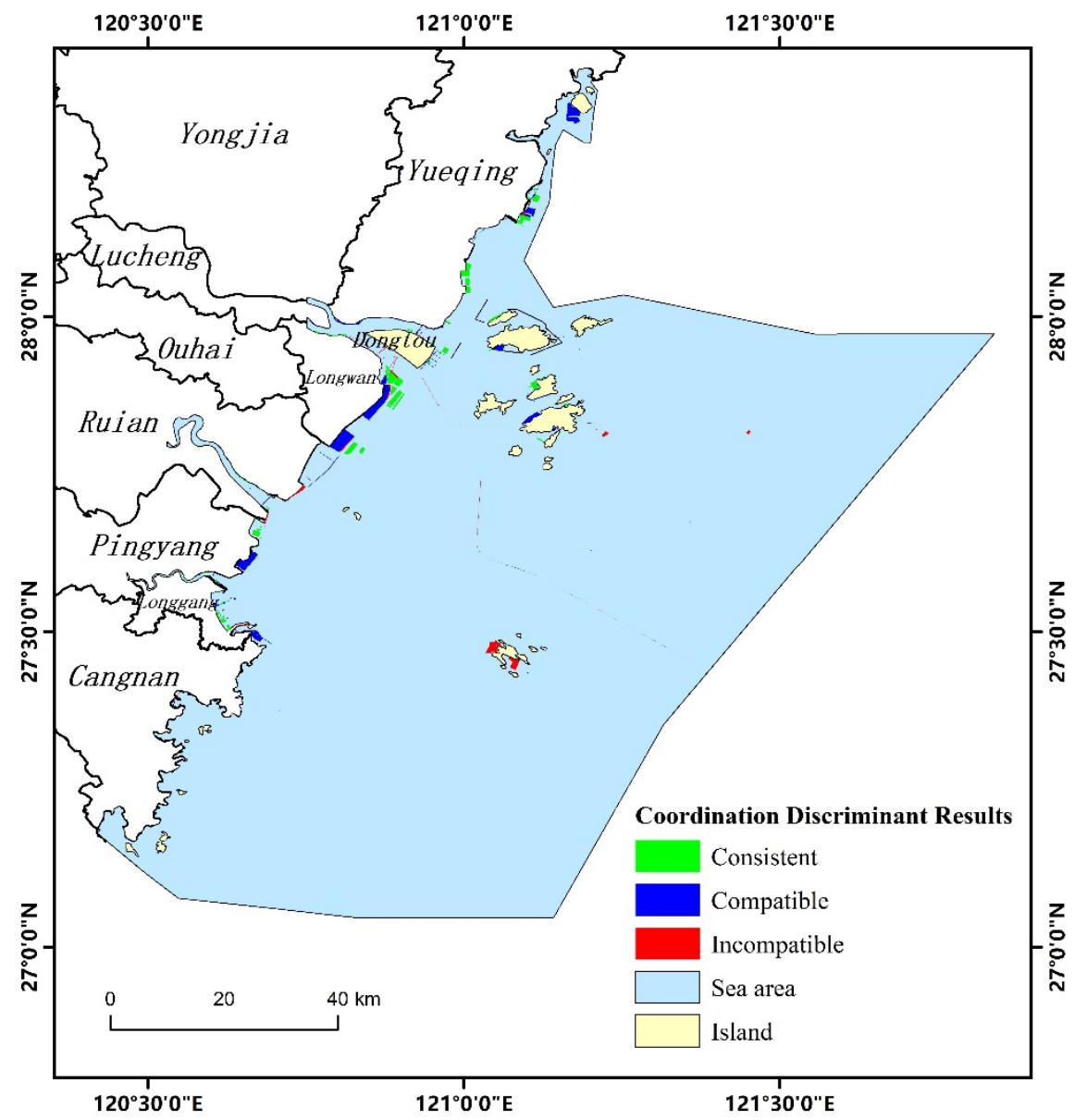

Figure 5. Coordination analysis between sea area utilization in Wenzhou from 2013 to 2020 and Wenzhou Marine Functional Zoning (2013-2020).

In addition, the construction of a marine functional zoning implementation evaluation method is of great significance to the compilation and implementation evaluation of the marine part of territorial space planning. On the one hand, marine functional zoning and other similar spatial planning evaluations are the basis and foundation of the compilation of the marine part of territorial spatial planning. The Ministry of Natural Resources has issued a number of documents emphasizing the importance of marine functional zoning, urban overall planning, land use overall planning and other spatial planning implementation evaluations and regard it as one of the basic tasks of the new round of territorial space planning. On the other hand, the implementation evaluation method of marine functional zoning can provide a reference for the planning evaluation of the searelated part of territorial spatial planning. In the existing marine planning implementation of planning standards and Wenzhou and other places, including all kinds of functional zoning, planning blueprints are still the main expression forms of the achievements of 
national spatial planning at all levels. Thus, as proposed in this paper, based on the concept of consistency and planning, the blueprint of planning implementation evaluation methods can be used as a future reference for the implementation of the national spatial planning evaluation logic, adjusting the evaluation standard, index parameters, etc.

\section{Conclusions}

Marine functional zoning is an important tool for governments at all levels to implement marine spatial governance, which is based on the carrying capacity and utilization suitability of marine ecosystem to allocate human activities for sea use, so as to realize the sustainability of the marine economy and the ecological environment. Based on the concept of consistency, this paper innovatively proposes the logic of judging the coordination between the current situation of sea area utilization and the blueprint of marine functional zoning and the integrated calculation method of the coordination index of marine functional zoning, taking Wenzhou as an example. The research shows that the coordination index between the sea area utilization in Wenzhou from 2013 to 2020 and the blueprint of the functional area in 2020 estimated by Wenzhou Marine Functional Zoning (2013-2020) is 0.81 , which shows that the implementation effect of Wenzhou marine functional zoning is good. The patch area of "incompatible" type accounts for $15.71 \%$. The main conflict types of farming and animal husbandry areas are developed into industrial sea, tourism and entertainment sea, and marine-protected areas are developed and utilized. The patch area of "compatible" type accounts for $14.87 \%$, which mainly includes the mixed utilization among ports, industry, urban construction and fishery infrastructure, and the layered mixed utilization among waterways, undersea tunnels, roads and bridges, indicating that Wenzhou's marine economy has made great progress in the mixed utilization and layered three-dimensional utilization of sea areas.

According to the evaluation results of coordination of marine functional zoning in Wenzhou, this paper puts forward the following three suggestions: (1) Adhere to the principle of ecological priority, strengthen the protection and construction of marine ecological environment in Wenzhou, improve the quality of marine environment and ensure regional environmental security. At the same time, adhere to the principle of marine ecological optimization and coordinated development of regional economy, change the mode of economic growth and support social and economic sustainable development with sustainable utilization of environment and resources. (2) Targeted measures should be taken in areas with serious ecological damage in the sea area, and the principle of ecological priority should be adhered to while ensuring the interests of the masses, combining prevention and control. Reduce the intensity of sea area use for uncoordinated conflicting sea areas and ban illegal sea-use projects. The existing marine environmental risk control and emergency capacity building is very weak, and there are obvious shortcomings in marine environmental law enforcement team, supervision ability and management means; in particular, the environmental supervision ability of coastal aquaculture and coastal engineering needs to be strengthened. (3) Fully consider the impact of land-based watershed and regional environmental pollution on the marine ecological environment, and strictly control the discharge of land-based pollutants to the ocean. At the same time, we should actively implement the combination of prevention and control to prevent the occurrence of marine pollution incidents and other incidents that damage the marine ecological environment.

Author Contributions: Conceptualization, R.M., B.Z. and J.L.; methodology, R.M. and J.L.; software, J.C.; validation, Q.P. and Y.C.; formal analysis, R.M. and W.W.; investigation, B.Z. and J.M.; resources, R.M.; data curation, J.C.; writing-original draft preparation, J.C., J.M. and J.L.; writing-review and editing, R.M., J.L. and J.C.; visualization, B.Z., supervision, R.M.; projection administration, R.M.; funding acquisition, R.M. All authors have read and agreed to the published version of the manuscript.

Funding: This research was funded by [Zhejiang Provincial Natural Science Foundation of China] grant number [LGF22D010002]. 
Data Availability Statement: All data used in this study are issued by China standard map service system and the Wenzhou government. This data can be found here: (http:/ /bzdt.ch.mnr.gov.cn/, accessed on 20 December 2021; http:/ / www.wenzhou.gov.cn/, accessed on 10 January 2022).

Conflicts of Interest: The authors declare no conflict of interest.

\section{References}

1. Ma, R.F.; Li, J.L.; Zhao, J.J. Progress on the research of maritime industry structure and layout in China. Geogr. Res. 2013, 32, 902-914.

2. Zhang, Y.F.; Zhang, Z.K.; Zhang, J.; Chen, H.Y. Research progress of marine spatial planning in the occident. Mar. Sci. Bull. 2013, 32, 352-360.

3. Ma, R.F.; Li, J.L. Difficulties and breakthrough countermeasures of integrating multiple planning in Ningbo coastal zone to support marine economic transformation. Port Econ. 2017, 17, 29-33.

4. Jiang, Y.M.; Li, J.L.; Ma, R.F.; Wu, D.D.; Wang, T.F.; Ye, M.Y. Integrated control of coastal zone based on the multiple planning integration. China Land Sci. 2018, 32, 34-39.

5. Faludi, A. A historical institutionalist account of European spatial planning. Plan. Perspect. 2018, 33, 1-15. [CrossRef]

6. Albrechts, L.; Healey, P.; Kunzmann, K.R. Strategic Spatial Planning and Regional Governance in Europe. J. Am. Plan. Assoc. 2003, 69, 113-129. [CrossRef]

7. Qian, H.; Luo, Z.D. Understanding the"Spatial Planning” Approach in Recent EU and the Implications for China. Int. Urban Plan. 2011, 26, 66-71.

8. Luukkonen, J. Planning in Europe for 'EU'rope: Spatial planning as a political technology of territory. Plan. Theory 2015, 14, 174-194. [CrossRef]

9. Faludi, A.; Waterhout, B. The Making of the European Spatial Development Perspective: No Masterplan; Routledge: London, UK, 2012.

10. Brenner, N. Urban governance and the production of new state spaces in Western Europe, 1960-2000. Rev. Int. Polit. Econ. 2004 11, 447-488. [CrossRef]

11. Assesment, M.E. Ecosystems and human well-being: Synthesis. Phys. Teach. 2005, 34, 534.

12. Dahl, R. Marine Spatial Planning: A Step-By-Step Approach toward Ecosystem-Based Management; Intergovernmental Oceanographic Commission: Paris, France, 2009.

13. Rempis, N.; Tsilimigkas, G. Marine spatial planning on Crete Island, Greece: Methodological and implementation issues. J. Spat. Sci. 2021, 2021, 1-20. [CrossRef]

14. Kyriazi, Z. From identification of compatibilities and conflicts to reaching marine spatial allocation agreements. Review of actions required and relevant tools and processes. Ocean. Coast. Manag. 2018, 166, 103-112. [CrossRef]

15. Maes, F. The international legal framework for marine spatial planning. Mar. Policy 2008, 32, 797-810. [CrossRef]

16. Coccossis, H. A bibliometric assessment of progress in marine spatial planning. Mar. Policy 2021, 127, 7801.

17. Proelss, A. United Nations Convention on the Law of the Sea; Springer: Berlin/Heidelberg, Germany, 2011.

18. Friess, B.; Grémaud-Colombier, M. Policy outlook: Recent evolutions of maritime spatial planning in the European Union. Mar. Policy 2021, 132, 103428. [CrossRef]

19. United Nations. Earth Summit: Agenda 21, the United Nations Programme of Action from Rio. 1993. Available online: https:/ / www.un.org/en/conferences/environment/rio1992 (accessed on 9 January 2022).

20. Balaguer, P.; Sarda, R.; Ruiz, M.; Diedrich, A.; Vizoso, G.; Tintore, J. A proposal for boundary delimitation for integrated coastal zone management initiatives. Ocean. Coast. Manag. 2008, 51, 806-814. [CrossRef]

21. Sellick, J. Towards a future maritime policy for the union: A European vision for the oceans and seas. Surg. J. R. Coll. Surg. Edinb. Irel. 2006, 26, 34-61.

22. Meiner, A. Integrated maritime policy for the European Union-Consolidating coastal and marine information to support maritime spatial planning. J. Coast. Conserv. 2010, 14,1-11. [CrossRef]

23. Pinkau, A.; Schiele, K.S. Strategic Environmental Assessment in marine spatial planning of the North Sea and the Baltic Sea-An implementation tool for an ecosystem-based approach? Mar. Policy 2021, 130, 104547. [CrossRef]

24. Douvere, F.; Ehler, C.N. New perspectives on sea use management: Initial findings from European experience with marine spatial planning. J. Environ. Manag. 2009, 90, 77-88. [CrossRef]

25. Spijkerboer, R.C.; Zuidema, C.; Busscher, T.; Arts, J. The performance of marine spatial planning in coordinating offshore wind energy with other sea-uses: The case of the Dutch North Sea. Mar. Policy 2020, 115, 103860. [CrossRef]

26. Soma, K.; van den Burg, S.W.; Selnes, T.; van der Heide, C.M. Assessing social innovation across offshore sectors in the Dutch North Sea. Ocean. Coast. Manag. 2019, 167, 42-51. [CrossRef]

27. Douvere, F.; Maes, F.; Vanhulle, A.; Schrijvers, J. The role of marine spatial planning in sea use management: The Belgian Case. Mar. Policy 2007, 31, 182-191. [CrossRef]

28. Alphen, V. The Voordelta integrated policy plan: Administrative aspects of coastal zone management in the Netherlands. Ocean. Coast. Manag. 1995, 26, 133-150. [CrossRef]

29. Fock, H.O. Fisheries in the context of marine spatial planning: Defining principal areas for fisheries in the German EEZ. Mar. Policy 2008, 32, 728-739. [CrossRef] 
30. Wang, Q.M.; Miao, F.M.; Li, S.Y. General situation of Marine Spatial Planning abroad and reference of marine functional zoning in China. Ocean. Dev. Manag. 2008, 25, 4.

31. Zhang, H.S. Outline of National Marine Functional Zoning; Ocean Press: Beijing, China, 2003.

32. State Oceanic Administration. Chinese Marine Functional Zoning in 2011 2020. 2012. Available online: http://www.gov.cn/ gzdt/2012-03/07/content_2085840.htm (accessed on 7 January 2022).

33. Yue, Q.; Xu, W.; Zhao, M.; Liu, S.F.; Liu, L.; Wang, H. Comparative study of marine function zoning plans between the new version and the last. Mar. Environ. Sci. 2014, 33, 487-488.

34. Tan, W.K.; Yuan, Y.; Feng, Y. Types and methods of urban planning implementation evaluation: A western literature review and its enlightenment. Planners 2019, 35, 75-81.

35. Carmona, M.; Sieh, L. Performance measurement innovation in English planning authorities. Plan. Theory Pract. 2005, 3, 303-333. [CrossRef]

36. Stelzenmüller, V.; Cormier, R.; Gee, K.; Shucksmith, R.; Gubbins, M.; Yates, K.L.; Morf, A.; Aonghusa, C.N.; Mikkelsen, E.; Tweddle, J.F.; et al. Evaluation of marine spatial planning requires fit for purpose monitoring strategies. J. Environ. Manag. 2021, 278, 111545. [CrossRef]

37. Laurian, L.; Day, M.; Berke, P.; Ericksen, N.; Backhurst, M.; Crawford, J.; Dixon, J. Evaluating plan implementation: A conformancebased methodology. J. Am. Plan. Assoc. 2004, 70, 471-480. [CrossRef]

38. Dhanak, M.; Parr, S.; Kaisar, E.I.; Goulianou, P.; Russell, H.; Kristiansson, F. Resilience assessment tool for port planning. Environ. Plan. B Urban Anal. City Sci. 2021, 3, 120-135. [CrossRef]

39. Faludi, A. The performance of spatial planning. Plan. Pract. Res. 2000, 15, 299-318. [CrossRef]

40. Ansong, O.; McElduff, L.; Ritchie, H. Institutional integration in transboundary marine spatial planning: A theory-based evaluative framework for practice. Ocean. Coast. Manag. 2021, 202, 105430. [CrossRef]

41. Zhu, L.X.; Dong, W.L.; Li, W.M. The development process, technical characteristics and evolution trend of urban planning implementation evaluation in China. J. Hum. Settl. West China 2019, 34, 67-73.

42. Li, S.J.; Wang, J.T.; Liu, J.; Wei, T.; Sun, R.J. Study on the framework of the marine planning system. Trans. Oceanol. Limnol. 2012, $33,129-136$.

43. Li, J.; Lin, N.; Xu, W.B. Research on spatial consistency between city and provincial marine functional zoning. Mar. Bull. China 2009, 28, 1-6.

44. Ding, Y.P.; Meng, X.; Xu, W.; Teng, X.; Dong, Y.E.; Yue, Q. Research on the conformance analysis method and judgement matrix for marine functional zoning. Mar. Environ. Sci. 2019, 38, 310-316.

45. Wang, J.T.; Liu, B.Q. Preliminary study on the compatibility discrimination methods of marine function zoning: A case study of port functional zones. Mar. Bull. China 2011, 30, 496-501.

46. Guo, Y.; Chen, W. A literature review of progress in regional plan assessment theory and methodology. Prog. Geogr. 2012, 31, 768-776.

47. Zhou, K.H.; Jiang, J.S. A review of urban planning evaluation in the west urban. Urban Plan. Forum 2013, 19, 104-109. 